\title{
Mechanical Properties of DO Run IIB Silicon Detector Staves
}

\author{
Giobatta Lanfranco and James Fast \\ Fermi National Accelerator Laboratory \\ Particle Physics Division /Mechanical Dep. - Silicon Engineering Group \\ e-mail: giobatta@fnal.gov,jfast@fnal.gov
}

14 June 2001

\section{Abstract}

A proposed stave design for the D0 Run IIb silicon tracker outer layers featuring central cooling channels and a composite shell mechanical structure is evaluated for self-deflection and deflection due to external loads. This paper contains an introduction to the stave structure, a section devoted to composite lamina and laminate properties and finally a section discussing the beam deflections expected for assembled staves using these laminates.

\section{The stave design}

The outermost layers of the detector are formed by twelve silicon sensors, $37.2 \mathrm{~mm}$ wide by $100 \mathrm{~mm}$ long, glued together into $1.2 \mathrm{~m}$ chains with readout electronics (hybrids) glued to the top surface. The spacing of the hybrids along the $1.2 \mathrm{~m}$ stave length is still under discussion, but is not critical to the mechanical studies presented in this paper. The stave is assembled starting from a central core consisting of three Rohacell foam (or other core material) strips interspersed with a pair of PEEK (or aluminum) cooling tubes. A thin $(0.10-0.2 \mathrm{~mm})$ surface ply of carbon fiber (or perhaps Kapton or pyrolitic graphite sheet) is adhesive bonded to the core material and cooling lines, as well as reinforced mounting points at the ends of the staves. These skins are primarily used for thermal management and are not included in the finite element analyses (FEA) presented below. The $1.2 \mathrm{~m}$ long silicon chains are bonded to either side of the core with axial strip readout on one side and small angle stereo strip readout on the other. Finally, two composite C-channels are attached around the silicon to form a box structure that provides most of the stave stiffness. An end-view of a stave is shown in Figure 1. The stave length is 48 " $(1.22 \mathrm{~m})$ with support provided at the center and the two ends. None of the supports 
Fermi National Accelerator Laboratory

Giobatta Lanfranco Silicon Engineering Group - Mechanical Dep.

are thought to provide a moment connection. We have also studied simple supports at only the ends of the staves, as this may be representative of the support condition at some stages of assembly.

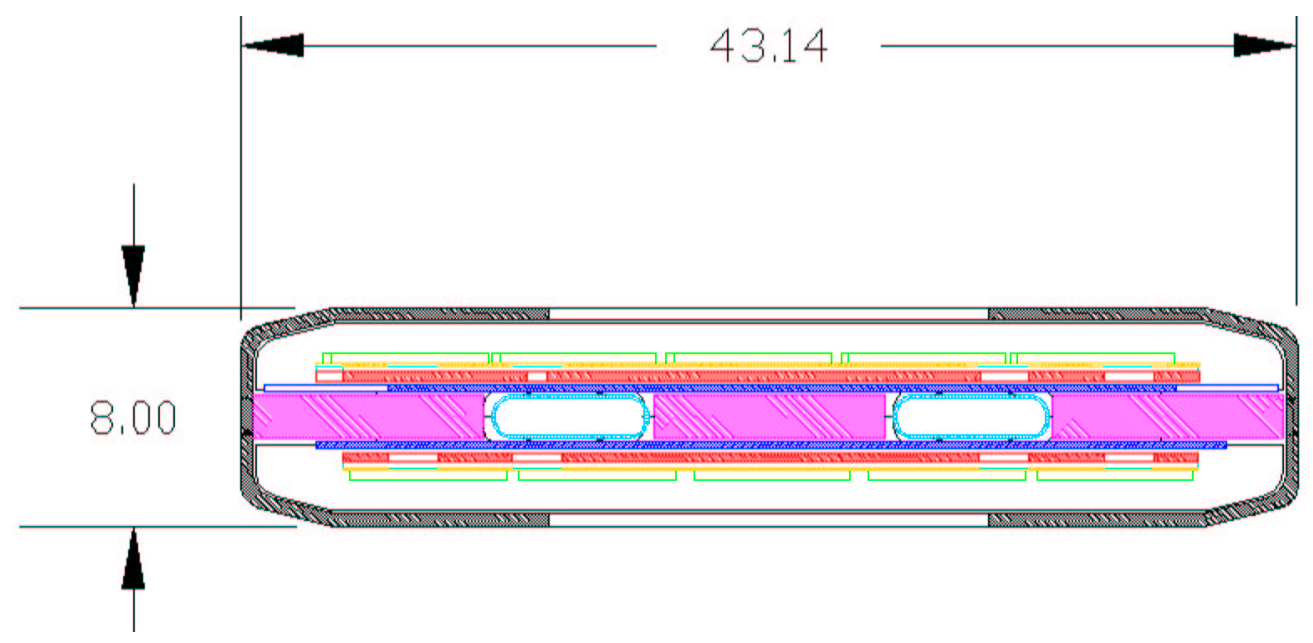

Figure 1-The ladder section

\begin{tabular}{cccc}
\hline Component & Material & $\begin{array}{c}\text { Thickness } \\
{[\mu \mathrm{m}]}\end{array}$ & Color in Figure 1 \\
\hline Support Shell & Carbon Fiber & 500 & black \\
\hline Sensor & Silicon & 300 & blue \\
\hline Chip & Silicon & 380 & green \\
\hline Glue & Epoxy & 50 & white \\
\hline Core & Rohacell & 2000 & magenta \\
\hline Tubing & PEEK & $\begin{array}{c}100 \\
\text { (wall thickness })\end{array}$ & cyan \\
\hline Heat spreader & Carbon Fiber & $\begin{array}{c}100 \\
(3 \text { plies } \mathrm{x} 33 \mu \mathrm{m})\end{array}$ & not shown \\
\hline HDI & Kapton & 100 & gold \\
\hline Substrate & BeO & 500 & red \\
\hline
\end{tabular}

Table 1 - Stave constituent materials 
Fermi National Accelerator Laboratory

Giobatta Lanfranco Silicon Engineering Group - Mechanical Dep.

\section{Development of laminate properties}

\subsection{Introduction}

The design of a silicon tracker stave must balance different requirements: providing a stiff, stable structural support for the silicon sensors, sufficiently matching the coefficient of thermal expansion of the silicon sensors in order to avoid thermal bowing and stress, limiting the amount of material so that multiple scattering will not affect the precision of the detector. The latter requirement is of much greater importance between the collision point and the second measurement point, however generation of secondaries (e.g. from photon conversions) is an issue throughout the detector volume.

This section presents a satisfactory carbon fiber lay-up and its performance; the results will be used in the following section to carry out a theoretical mechanical analysis of the present D0 stave design in order to verify its structural feasibility.

In order to meet both the mechanical stiffness requirements and the desired thermal expansion for the composites, previous ladder rails for D0 and CDF have utilized Hybor, a boron/carbon mix manufactured by Textron. Boron fiber is produced by chemical vapor deposition on a tungsten wire substrate. Although in the past Textron produced some boron fibers on a carbon fiber substrate, due to production difficulties the boron fiber is only available with a tungsten wire core at this time. The result is a composite with a relatively low radiation length, about $13 \mathrm{~cm}$ vs. $25 \mathrm{~cm}$ for a carbon fiber laminate.

\subsection{Laminae and laminate properties}

The laminae are the individual plies of fiber pre-impregnated with resin used to build up composite laminates (plates or structures).

Table 2 and

Table 3 summarize the physical properties of the boron and carbon laminae used in this study.

Table 4,

Table 5 and Table 6 contain the laminate lay-up and theoretical laminate properties for three possible laminae configurations that closely match the CTE of silicon. The first and third use both boron and carbon while the second uses only carbon. For a carbon only laminate the fibers cannot be oriented along the longitudinal direction or the CTE will be reduced to near 0 . The result is that the longitudinal stiffness, $E_{x}$, of the carbon-only lay-up is about $1 / 4$ that of the carbon/boron mix. This lay-up is 
Fermi National Accelerator Laboratory

Giobatta Lanfranco Silicon Engineering Group - Mechanical Dep.

considered for sections of the stave shell that are involved only in carrying shear and which will be largely cut away to reduce mass, rendering longitudinal fibers in these regions ineffective.

\section{Boron 5505/4}

\begin{tabular}{||c|c||}
\hline E1 & $186.2 \mathrm{Gpa}$ \\
E2 & $18.6 \mathrm{Gpa}$ \\
E3 & $18.6 \mathrm{Gpa}$ \\
G12 & $6.2 \mathrm{Gpa}$ \\
G13 & $0.1 \mathrm{Gpa}$ \\
G23 & $0.1 \mathrm{Gpa}$ \\
NU12 & 0.21 \\
NU13 & 0.21 \\
NU23 & 0.41 \\
CTE1 & $3.06 \mathrm{E}-06 \mathrm{~mm} / \mathrm{mm} / \mathrm{C}$ \\
CTE2 & $2.36 \mathrm{E}-05 \mathrm{~mm} / \mathrm{mm} / \mathrm{C}$ \\
CTE3 & $2.36 \mathrm{E}-05 \mathrm{~mm} / \mathrm{mm} / \mathrm{C}$ \\
E1 & $6.55 \mathrm{E}-03 \mathrm{~mm} / \mathrm{mm}$ \\
E2 & $4.10 \mathrm{E}-03 \mathrm{~mm} / \mathrm{mm}$ \\
E12 & $1.48 \mathrm{E}-02 \mathrm{~mm} / \mathrm{mm}$ \\
E1 & $-1.25 \mathrm{E}-04 \mathrm{~mm} / \mathrm{mm}$ \\
E2 & $-1.78 \mathrm{E}-04 \mathrm{~mm} / \mathrm{mm}$ \\
E12 & $-1.48 \mathrm{E}-02 \mathrm{~mm} / \mathrm{mm}$ \\
Density & $2.01 \mathrm{~g} / \mathrm{cm} 3$ \\
\hline \hline
\end{tabular}

Table 2- Physical properties of boron fiber prepreg 
Fermi National Accelerator Laboratory

Giobatta Lanfranco Silicon Engineering Group - Mechanical Dep.

\begin{tabular}{||c|c||}
\hline \multicolumn{2}{|c|}{ k139-1515-70/30 } \\
\hline E1 & $424.7 \mathrm{GPa}$ \\
E3 & $5.9 \mathrm{GPa}$ \\
G12 & $5.9 \mathrm{GPa}$ \\
G13 & $2.2 \mathrm{GPa}$ \\
G23 & $2.2 \mathrm{GPa}$ \\
NU12 & $1.3 \mathrm{GPa}$ \\
NU13 & 0.32 \\
NU23 & 0.32 \\
CTE1 & $-1.26 \mathrm{E}-06 \mathrm{~mm} / \mathrm{mm} / \mathrm{C}$ \\
CTE2 & $2.16 \mathrm{E}-05 \mathrm{~mm} / \mathrm{mm} / \mathrm{C}$ \\
CTE3 & $2.16 \mathrm{E}-05 \mathrm{~mm} / \mathrm{mm} / \mathrm{C}$ \\
E1 & $5.16 \mathrm{E}-03 \mathrm{~mm} / \mathrm{mm}$ \\
E2 & $9.19 \mathrm{E}-02 \mathrm{~mm} / \mathrm{mm}$ \\
E12 & $1.76 \mathrm{E}-02 \mathrm{~mm} / \mathrm{mm}$ \\
E1 & $-1.36 \mathrm{E}-03 \mathrm{~mm} / \mathrm{mm}$ \\
E2 & $-2.18 \mathrm{E}-02 \mathrm{~mm} / \mathrm{mm}$ \\
E12 & $-1.76 \mathrm{E}-02 \mathrm{~mm} / \mathrm{mm}$ \\
Density & $1.71 \mathrm{~g} / \mathrm{cm} 3$ \\
\hline \hline
\end{tabular}

Table 3 - Physical properties of carbon fiber prepreg 
Fermi National Accelerator Laboratory

Giobatta Lanfranco Silicon Engineering Group - Mechanical Dep.

Boron 5505/4 + k139-1515-70/30

\begin{tabular}{cccc}
\hline Ply \# & Lamina Type & Thickness & Angle \\
\hline 1 & k139-1515-70/30 & 55 & 54 \\
2 & Boron 5505/4 & 135 & 0 \\
3 & k139-1515-70/30 & 55 & -54 \\
4 & k139-1515-70/30 & 55 & -54 \\
5 & Boron 5505/4 & 135 & 0 \\
6 & k139-1515-70/30 & 55 & 54 \\
\hline
\end{tabular}

\begin{tabular}{||c|c||}
\hline Ex (pa) & $106.2 \mathrm{GPa}$ \\
Ey (pa) & $77.5 \mathrm{GPa}$ \\
Ez (pa) & $15.7 \mathrm{GPa}$ \\
Gxy (pa) & $46.9 \mathrm{GPa}$ \\
Gxz (pa) & $0.8 \mathrm{GPa}$ \\
Gyz (pa) & $0.9 \mathrm{GPa}$ \\
NUxy & 0.49 \\
NUyx & 0.36 \\
NUxz & 0.14 \\
NUzx & 0.02 \\
NUyz & 0.31 \\
NUzy & 0.06 \\
CTEx & $2.50 \mathrm{E}-06 \mathrm{~mm} / \mathrm{mm} / \mathrm{C}$ \\
CTEy & $1.03 \mathrm{E}-07 \mathrm{~mm} / \mathrm{mm} / \mathrm{C}$ \\
CTEz & $3.31 \mathrm{E}-05 \mathrm{~mm} / \mathrm{mm} / \mathrm{C}$ \\
Density & $1.875 \mathrm{~g} / \mathrm{cm} 3$ \\
Thickness & $490 \mathrm{Micron}$ \\
\hline \hline
\end{tabular}

Table 4 - Lay-up and properties of the laminate containing boron 
Fermi National Accelerator Laboratory

Giobatta Lanfranco Silicon Engineering Group - Mechanical Dep.

k139-1515-70/30

\begin{tabular}{cccc}
\hline Ply \# & Lamina Type & Thickness & Angle \\
\hline 1 & k139-1515-70/30 & 80 & 90 \\
2 & k139-1515-70/30 & 80 & 53 \\
3 & k139-1515-70/30 & 80 & -53 \\
4 & k139-1515-70/30 & 80 & -53 \\
5 & k139-1515-70/30 & 80 & 53 \\
6 & k139-1515-70/30 & 80 & 90
\end{tabular}

\begin{tabular}{||c|c||}
\hline Ex (pa) & $25.7 \mathrm{GPa}$ \\
Ey (pa) & $156.3 \mathrm{GPa}$ \\
Ez (pa) & $8.1 \mathrm{GPa}$ \\
Gxy (pa) & $66.7 \mathrm{GPa}$ \\
Gxz (pa) & $1.5 \mathrm{GPa}$ \\
Gyz (pa) & $2.0 \mathrm{GPa}$ \\
NUxy & 0.26 \\
NUyx & 1.56 \\
NUxz & 0.42 \\
NUzx & 0.13 \\
NUyz & -0.34 \\
NUzy & -0.02 \\
CTEx & $2.47 \mathrm{E}-06 \mathrm{~mm} / \mathrm{mm} / \mathrm{C}$ \\
CTEy & $-1.96 \mathrm{E}-06 \mathrm{~mm} / \mathrm{mm} / \mathrm{C}$ \\
CTEz & $3.29 \mathrm{E}-05 \mathrm{~mm} / \mathrm{mm} / \mathrm{C}$ \\
Density & $1.714 \mathrm{~g} / \mathrm{cm} 3$ \\
Thickness & $480 \mathrm{micron}$ \\
\hline \hline
\end{tabular}

Table 5 - Lay-up and properties of the laminate containing only carbon fiber 
Fermi National Accelerator Laboratory

Giobatta Lanfranco Silicon Engineering Group - Mechanical Dep.

\begin{tabular}{cccc}
\multicolumn{4}{c}{ Boron 5505/4 + k139-1515-70/30 - ALTERNATIVE } \\
\hline Ply \# & Lamina Type & Thickness & Angle \\
\hline 1 & Boron 5505/4 & 135 & 0 \\
2 & k139-1515-70/30 & 55 & 53 \\
3 & k139-1515-70/30 & 55 & -53 \\
4 & k139-1515-70/30 & 55 & -53 \\
5 & k139-1515-70/30 & 55 & 53 \\
6 & Boron 5505/4 & 135 & 0
\end{tabular}

\begin{tabular}{||c|c||}
\hline Ex (pa) & $106.5 \mathrm{GPa}$ \\
Ey (pa) & $73.1 \mathrm{GPa}$ \\
Ez (pa) & $15.7 \mathrm{GPa}$ \\
Gxy (pa) & $47.8 \mathrm{GPa}$ \\
Gxz (pa) & $0.8 \mathrm{GPa}$ \\
Gyz (pa) & $0.9 \mathrm{GPa}$ \\
NUxy & 0.52 \\
NUyx & 0.36 \\
NUxz & 0.13 \\
NUzx & 0.02 \\
NUyz & 0.31 \\
NUzy & 0.07 \\
CTEx & $2.39 \mathrm{E}-06 \mathrm{~mm} / \mathrm{mm} / \mathrm{C}$ \\
CTEy & $1.91 \mathrm{E}-07 \mathrm{~mm} / \mathrm{mm} / \mathrm{C}$ \\
CTEz & $3.31 \mathrm{E}-05 \mathrm{~mm} / \mathrm{mm} / \mathrm{C}$ \\
Density & $1.875 \mathrm{~g} / \mathrm{cm} 3$ \\
Thickness & $490 \mathrm{micron}$ \\
\hline \hline
\end{tabular}

Table 6 - Lay-up and properties of the alternative boron laminate 
Fermi National Accelerator Laboratory

Giobatta Lanfranco Silicon Engineering Group - Mechanical Dep.

\section{Deflections of stave structures}

\subsection{Structural configuration}

Four different configurations for the laminate structure have been considered (Figure 2). The first configuration is a structure made with boron/carbon mix throughout the shell. This is not desirable from a radiation length standpoint due to the tungsten filaments in the boron fibers and from a fabrication standpoint as it will be very difficult to cut through the boron fibers to make the windows to bring cables out through. The second configuration is all carbon fiber. As mentioned above, the longitudinal stiffness of this lay-up is very low and the deflections are unacceptably large. The third configuration has boron/carbon mix in C-shaped regions on the two sides of the structure. These provide the longitudinal stiffness and allow the windows to be cut through pure carbon regions down the center of the structure. The forth configuration is very similar to the third, except that the boron has also been removed from the vertical (side) members to further reduce the mass. Analysis of the effects of large area windows cut in the C-channels are beyond the scope of this study and will require fabrication and load testing of prototype structures.

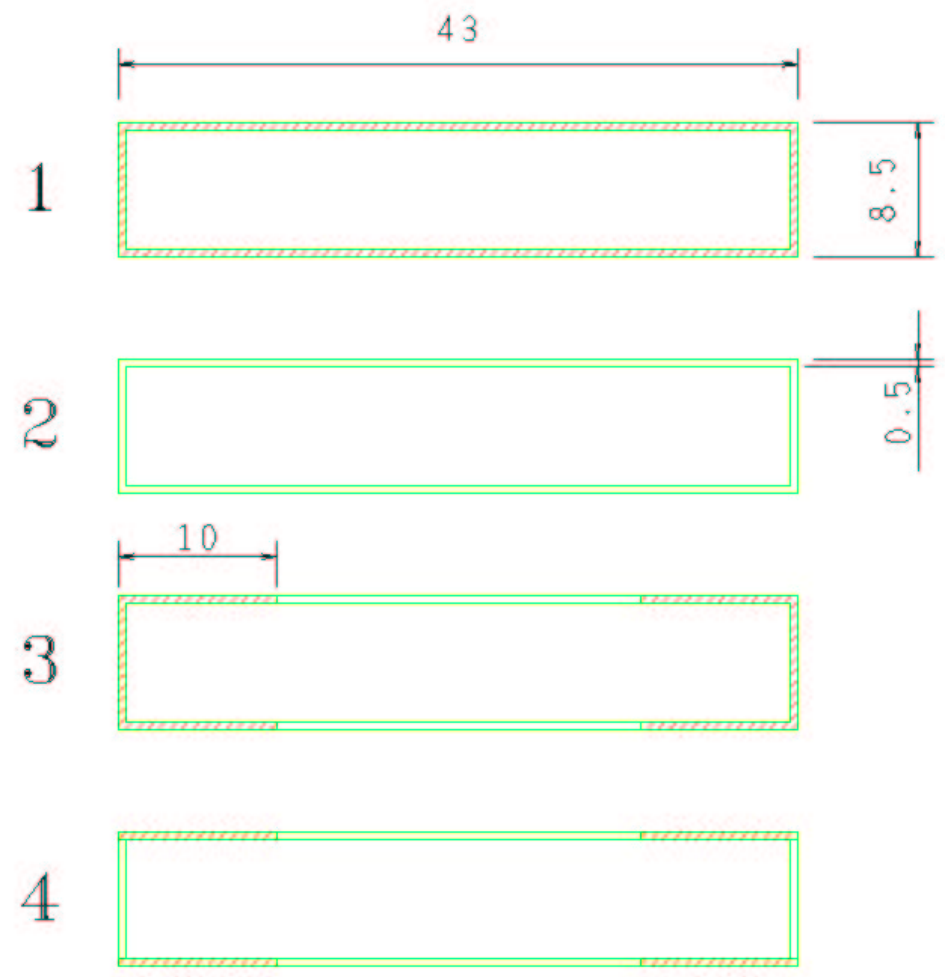

Figure 2 - Material Configurations (the Boron prepreg appears hatched). Dimensions in mm. 
Fermi National Accelerator Laboratory

Giobatta Lanfranco Silicon Engineering Group - Mechanical Dep.

\subsection{Analytical study}

As a starting point the bending and torsional stiffness of the four shell configurations were calculated analytically. The results are presented in Figure 3. As expected the second configuration, which has only carbon fibers at large angles to the long axis of the stave, shows very low bending stiffness. The first case has the highest bending stiffness, but the material content required to achieve this would be unacceptable. The last two cases offer a reasonable balance between beam stiffness and material content and are representative of the objects that are envisioned for use in the detector.

Stiffness Comparison

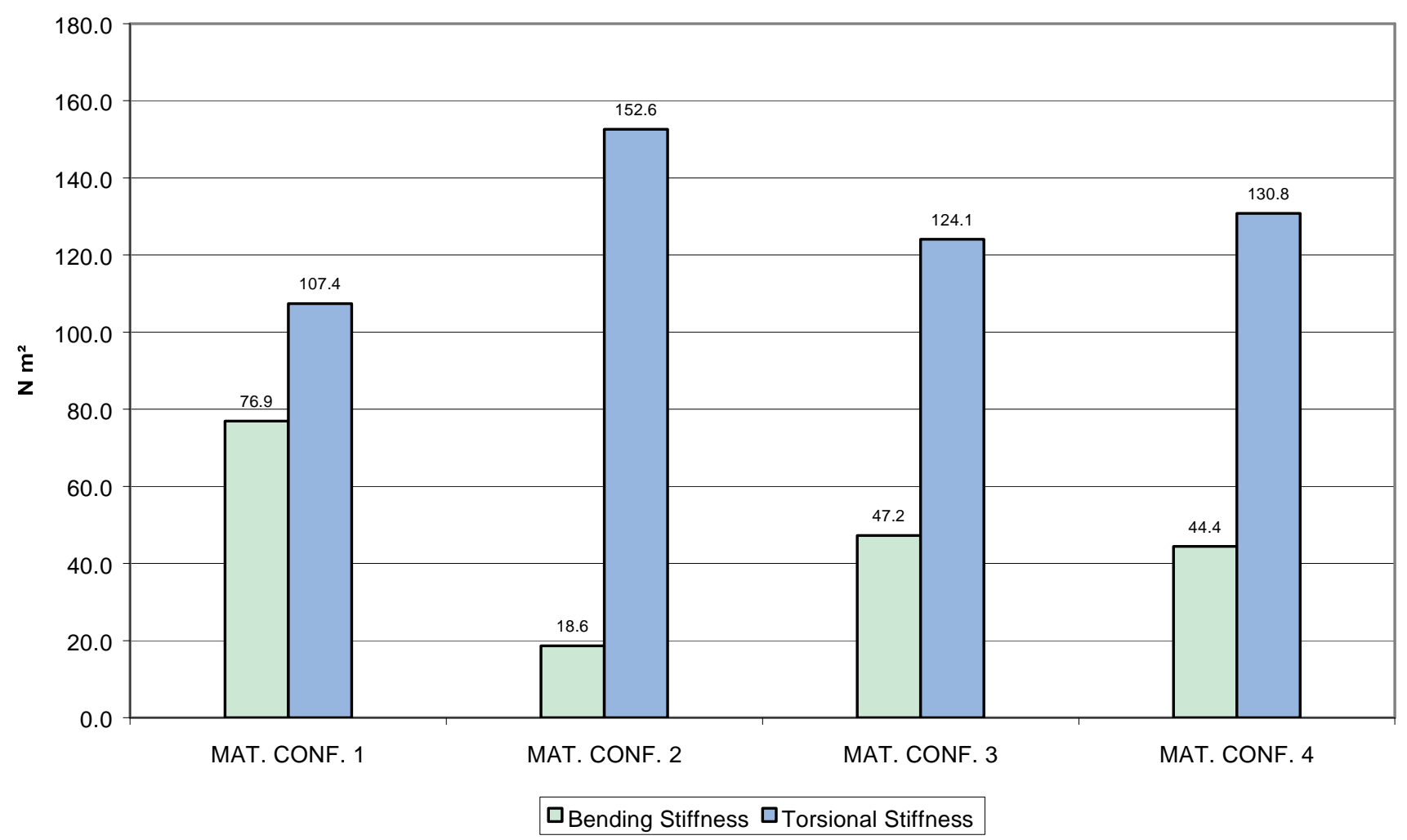

Figure 3 - Theoretical stiffness comparison.

The critical concern is the deflection of the silicon sensors due to gravitational loads and due to external loading, e.g. cooling line connections and cables. Staves will be mounted in all orientations so we have studied the deflections for staves oriented as shown in Figure 1 (horizontal configuration - X) and rotated 90 degrees (vertical configuration - Y).

Although a portion of the load is concentrated in the hybrid regions, we have modeled the stave load as uniform along the full length with a value of $2.1 \mathrm{~N} / \mathrm{m}(0.012 \mathrm{lbs} / \mathrm{in})$. Point loads were applied centered 
between support points to simulate potential loads induced by cables at the hybrid location, or by handling during assembly. Finally, moment loads were applied to the ends of the staves, simulating effects of the cooling and cable connections from the staves to the outside world (unit loads were applied and one should scale the results as appropriate for realistic load estimates) or possible misalignment of the supports. Summarizing results are presented for three load cases

1. gravity

2. $4.9 \mathrm{~N}(\sim 1.1 \mathrm{lbf})$ concentrated load half the way between two supports (equivalent to the load transmitted by a mass of $0.5 \mathrm{~kg}$ )

3. $0.113 \mathrm{~N} \cdot \mathrm{m}(1 \mathrm{lbf})$ torque at the stave ends

and assuming three different support conditions

1. simple support at each end;

2. fixed support at each end;

3. simple support at the middle and ends of the stave $\mathrm{e}^{1}$.

Configuration 4 (see Figure 2) provides the best overall behaviour in terms of stiffness and radiation length;it has been used for the deflection results presented in Figure 4, the stresses in the silicon in Figure 5 and the stresses in the composite shell structure in Figure 6. The first support case is typical of what may be experienced during assembly handling so the deflections are not a concern, but the stress levels are. To set the scale for the stresses, the published silicon yield stress is $120 \mathrm{MPa}$ and that for the composites is around 1500-2200 MPa. For the silicon one should be careful as stress concentrations from defects along the cut edges can significantly increase the local stress above the nominal stresses presented in Figure 5, leading to failure under much lower load conditions than the naïve expectation. In this case the factors of safety are extremely generous and one would not anticipate any materials failures ${ }^{2}$. We do not think that the second support condition is realizable in the detector assembly, but present it for completeness. The third support condition is what we anticipate for the final mounting condition of the staves. Here it is the deflections that are critical. Figure 4 shows that the self-deflection is well under control at $\sim 30$ microns. The deflection due to

\footnotetext{
${ }^{1}$ In this case, for load condition 2, loads are applied at the midpoints of both of the unsupported spans.

${ }^{2}$ Cantilever support of the stave from one end will increase the stresses by a factor of 4 , still well below any conceivable failure point. If, however, a partially assembled stave without the outer structure were to be simply supported from the ends the deflection would be around 50mm and the stress in the silicon would be about $15 \mathrm{Mpa}$ which may be a concern given the possibility of stress fractures originating from defects along the cut edges.
} 
Fermi National Accelerator Laboratory

Giobatta Lanfranco Silicon Engineering Group - Mechanical Dep.

external loads of $4.9 \mathrm{~N}$ on each unsupported span should be scaled down by at least a factor of ten given the expected loading one might see in the as-installed condition.

Finally, it should be noted that the natural frequency of the staves (Figure 7) are closely related to the maximum deflection under self-loading ${ }^{3}$. For deflections above 50 microns the natural frequency is dropping into the $60 \mathrm{~Hz}$ range, which we feel should be avoided. Therefore the maximum acceptable beam deflection is driven by the requirement of staying sufficiently far above a natural frequency of $60 \mathrm{~Hz}$ rather than the maximum allowable for the required sensor alignment tolerances needed for the vertex trigger ( 200 microns).

Overall Contribution to Deflection

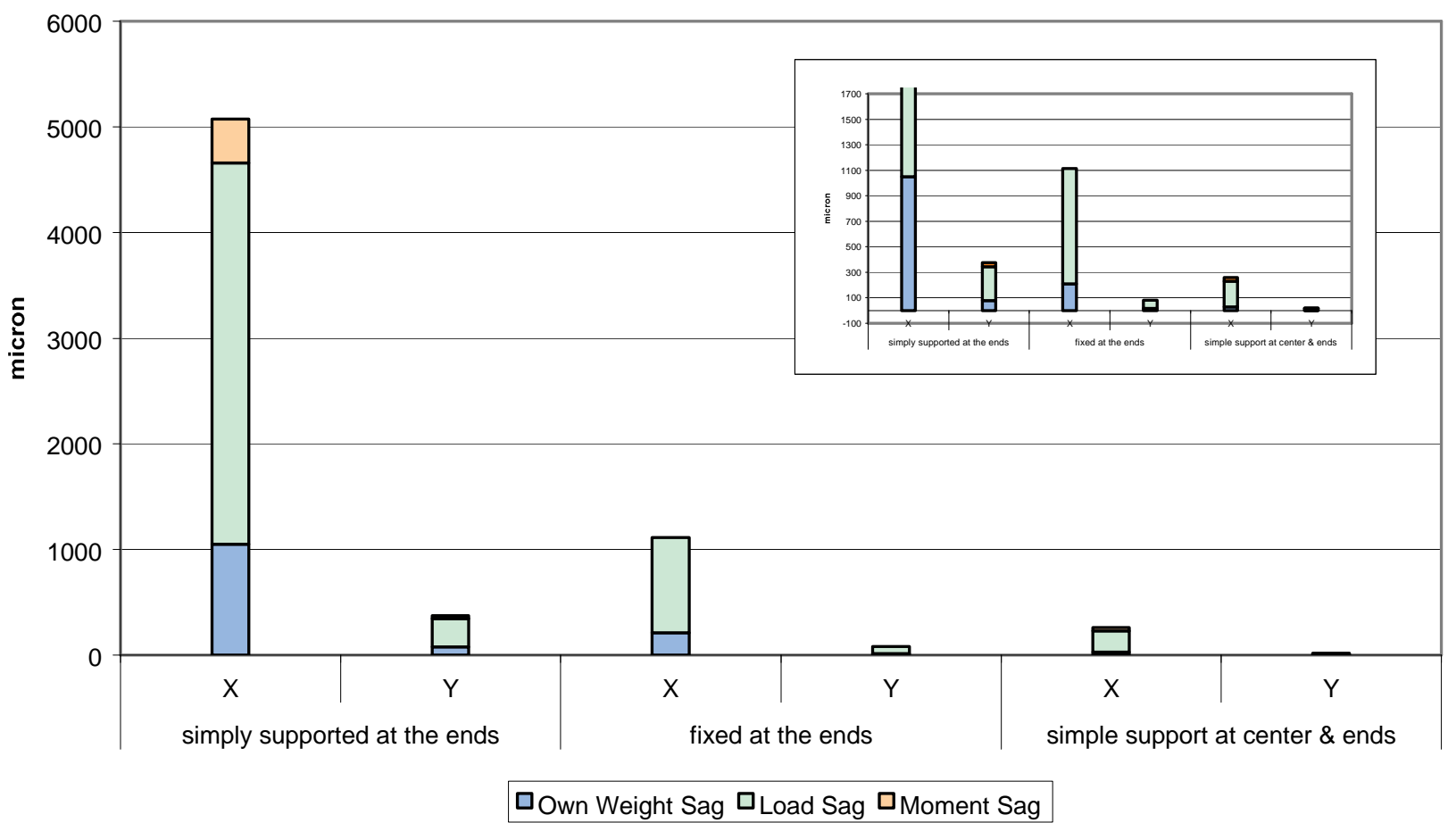

Figure 4-Overall deflection

\footnotetext{
${ }^{3}$ The natural frequency is, to good approximation, directly proportional to the square root of the maximum deflection.
} 
Fermi National Accelerator Laboratory

Giobatta Lanfranco Silicon Engineering Group - Mechanical Dep.

Total Bending Stresses in Silicon

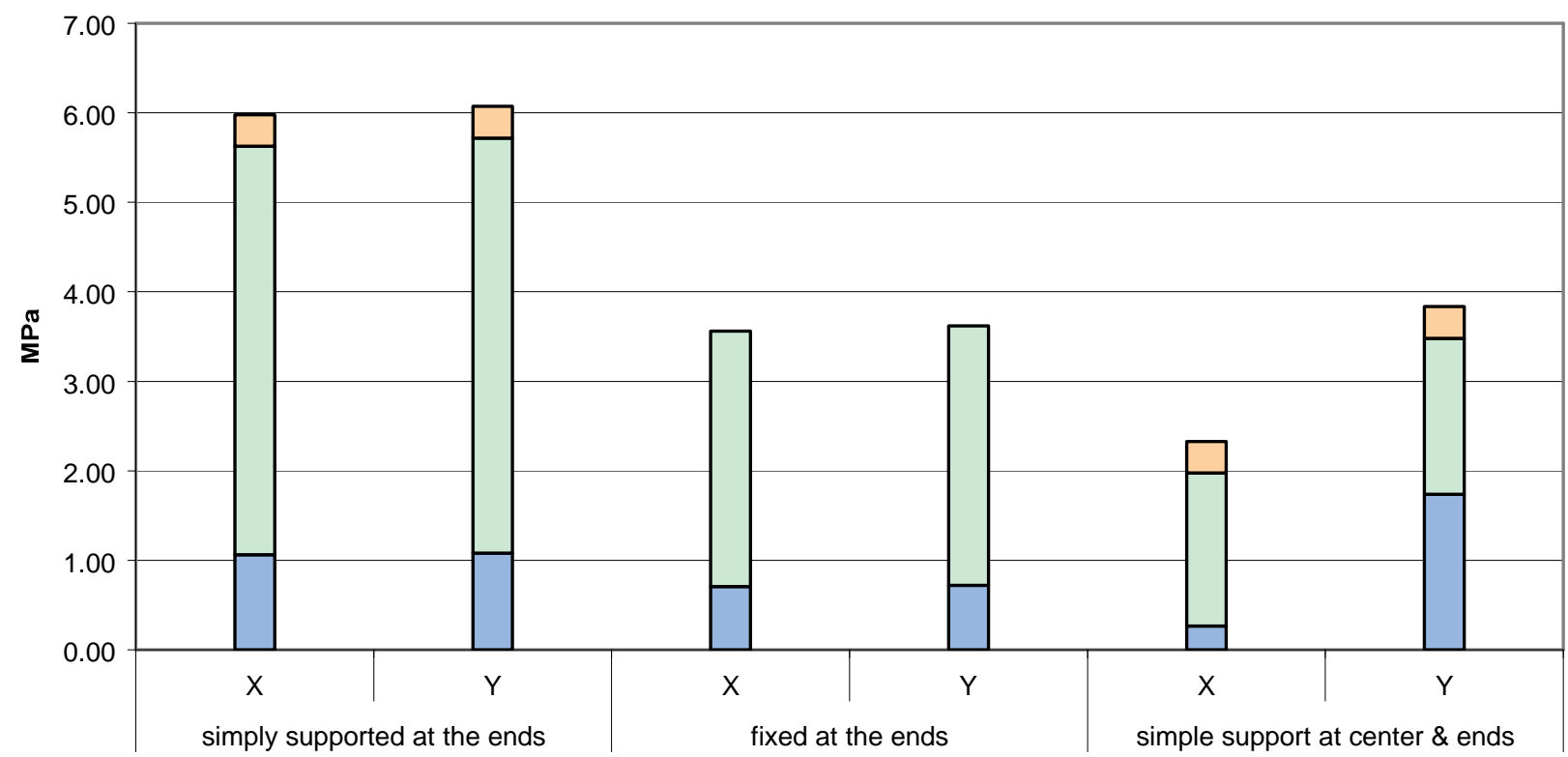

$\square$ Si own weight stress $\square$ Si Ext Load stress $\square$ Si Moment stress

Figure 5 - Bending stresses in the silicon sensor

Total Bending Stresses in CF Structure

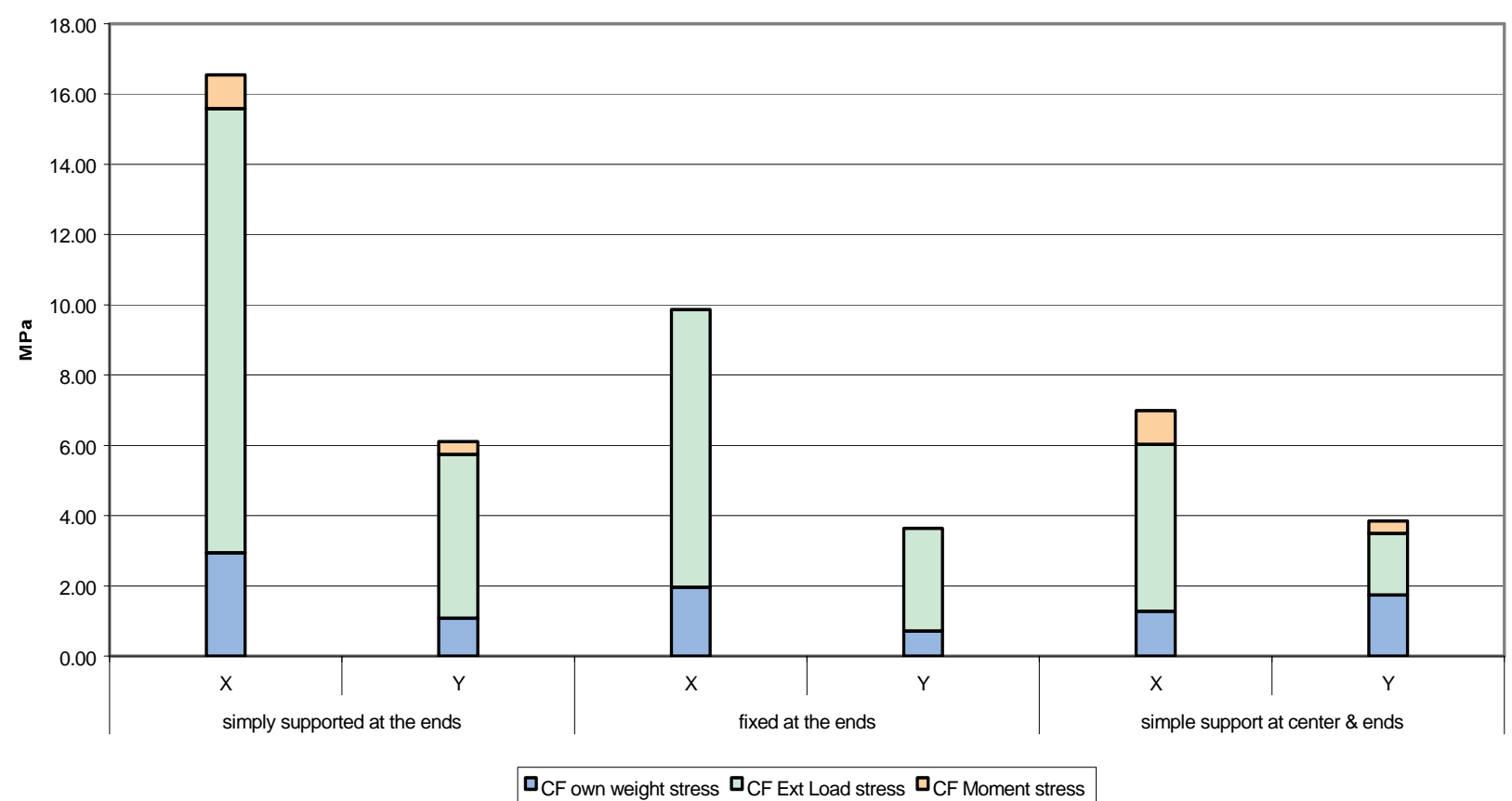

Figure 6-Bending stresses in the carbon fiber structure 


\section{Fundamental Frequencies}

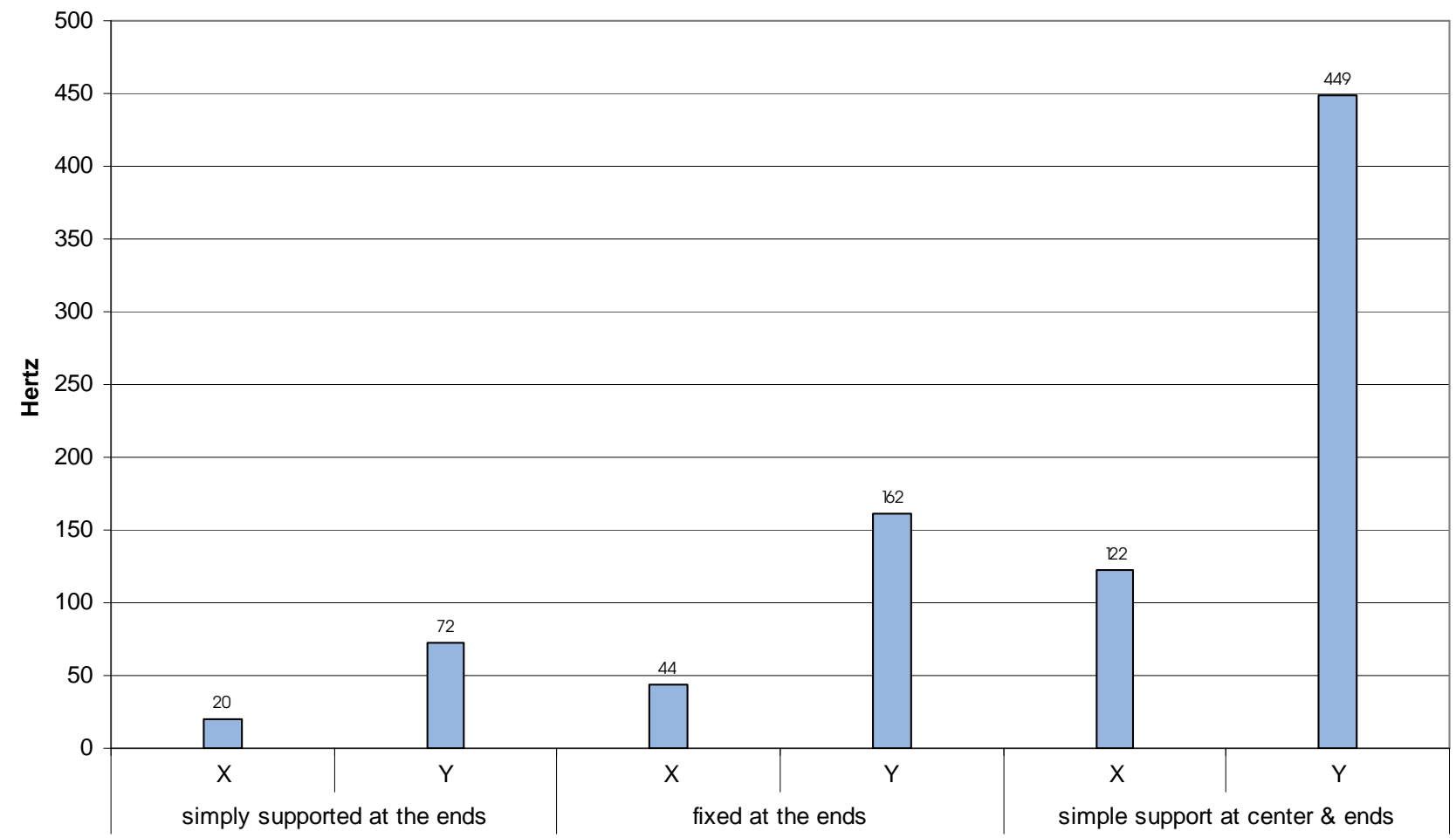

Figure 7 - Calculated stave fundamental frequencies

\subsection{Finite element analysis}

We consider, in addition to the theoretical investigation, a simple finite element model of the stave outer shell. The model has a longitudinal length of $10 \mathrm{~mm}$ with one end fully constrained around the perimeter. Two load cases are depicted in Figure 8: 1) a longitudinally distributed torque totaling 10 $\mathrm{N} \cdot \mathrm{m}$ and 2) two longitudinally distributed loads, totaling $20 \mathrm{~N}$, applied along the edges of the stave. in The results of the FEA are shown in Figure 9 through Figure 16 and the displacements summarized in Table 7. Material configuration 4 provides the best torsional performance and a flexural behaviour comparable to the other configurations. 
Fermi National Accelerator Laboratory

Giobatta Lanfranco Silicon Engineering Group - Mechanical Dep.
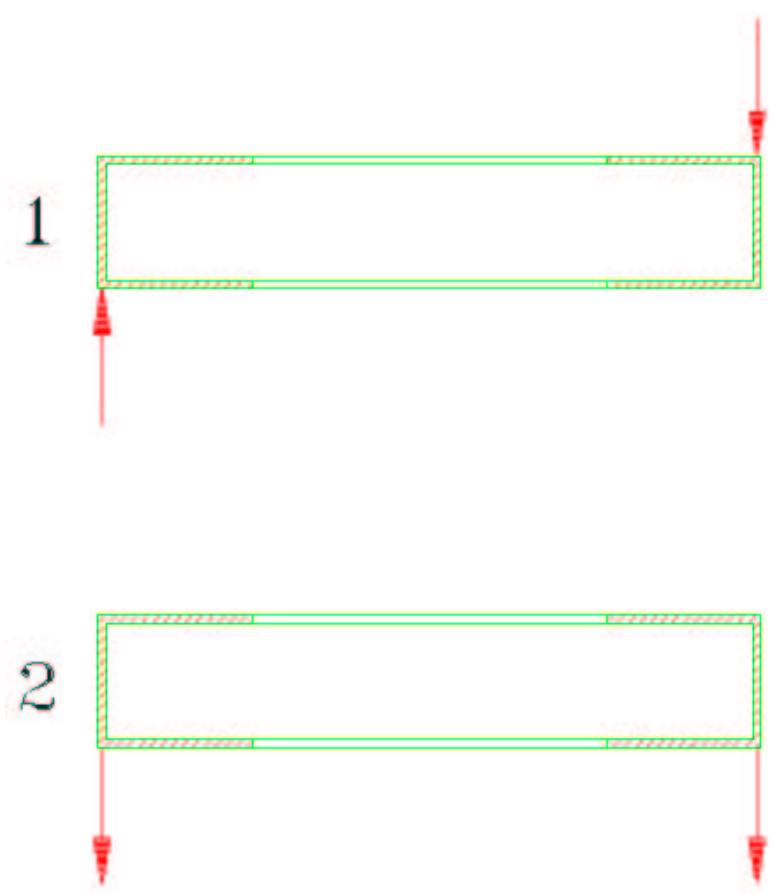

Figure 8-Load Cases. Case 1: 10 N.m ( 88.5 lbf in) torque distributed along the longitudinal length. Case 2: $10 \mathrm{~N} x 2$ $(\sim 2.25 \mathrm{lbf} x 2)$ distributed along the longitudinal length

\begin{tabular}{c|cc}
\hline $\begin{array}{c}\text { Configuration } \\
{[\text { material - load] }}\end{array}$ & $\begin{array}{c}\text { min displacement } \\
{[\mu \mathrm{m}]}\end{array}$ & $\begin{array}{c}\text { max displacement } \\
{[\mu \mathrm{m}]}\end{array}$ \\
\hline 1-torsion & .1 & 13 \\
\hline 1-flexure & 0.2 & 0.8 \\
\hline 2-torsion & 0 & 17 \\
\hline 2-flexure & 0.3 & 1.1 \\
\hline 3-torsion & 0 & 13 \\
\hline 3-flexure & 0.2 & 0.8 \\
\hline 4-torsion & 1 & 11 \\
\hline 4-flexure & 0.3 & 0.8 \\
\hline
\end{tabular}

Table 7 - Finite element analysis displacement summary. 
Fermi National Accelerator Laboratory

Giobatta Lanfranco Silicon Engineering Group - Mechanical Dep.

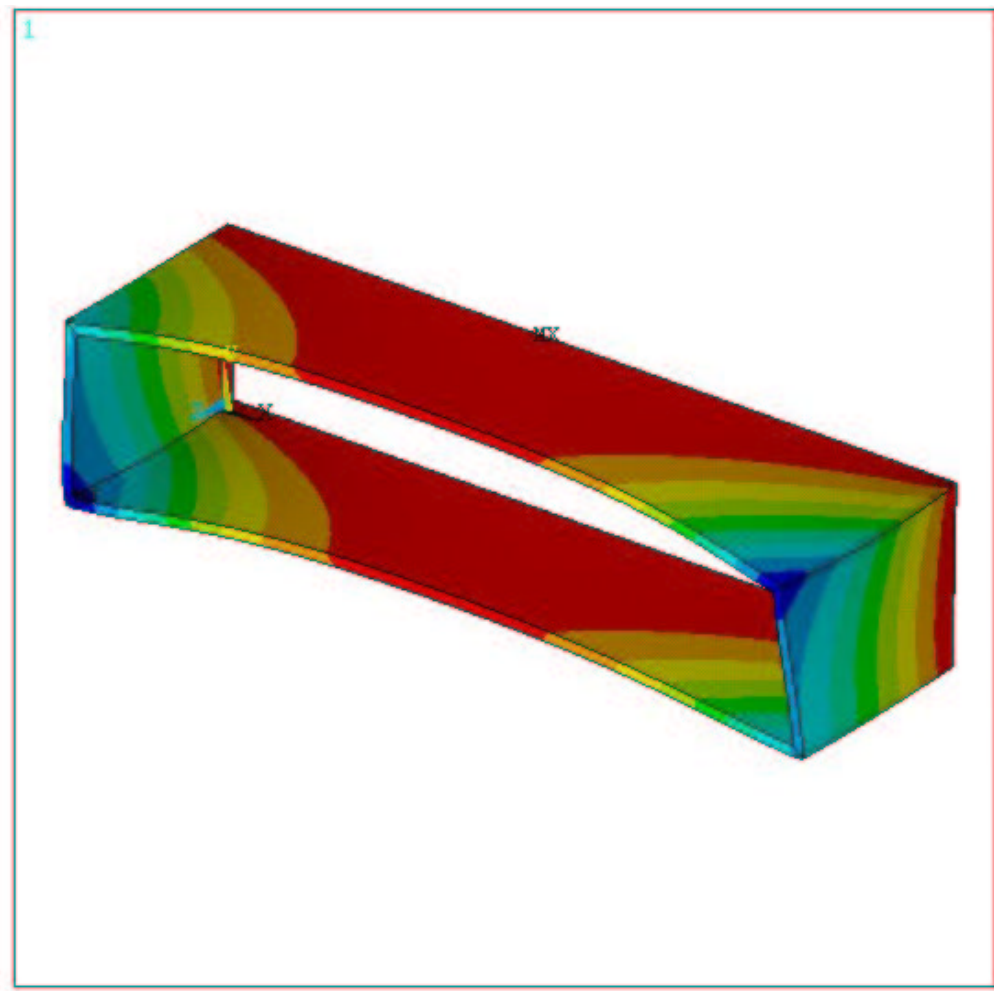

ANSYS 5.5.3

MAY 102001

$10: 56: 58$

NODAL SOLUTION

$\mathrm{STEP}=1$

SUB $=1$

T IME $=1$

UY

RSYS $=0$

(AVG)

PowerGraphics

EFACET $=1$

AVRES $=$ Mat

$\mathrm{DMX}=.133 \mathrm{E}-04$

$\mathrm{SMN}=-.129 \mathrm{E}-04$

$\mathrm{SMX}=.113 \mathrm{E}-06$

$-.129 \mathrm{E}-04$

$-.114 \mathrm{E}-04$
$-.999 \mathrm{E}-05$

$-.855 \mathrm{E}-05$

$-.710 \mathrm{E}-05$

$-.566 \mathrm{E}-05$

$-.422 \mathrm{E}-05$

$-.133 \mathrm{E}-05$

$.113 \mathrm{E}-06$

Figure 9 - Material Configuration 1, Load Case 1

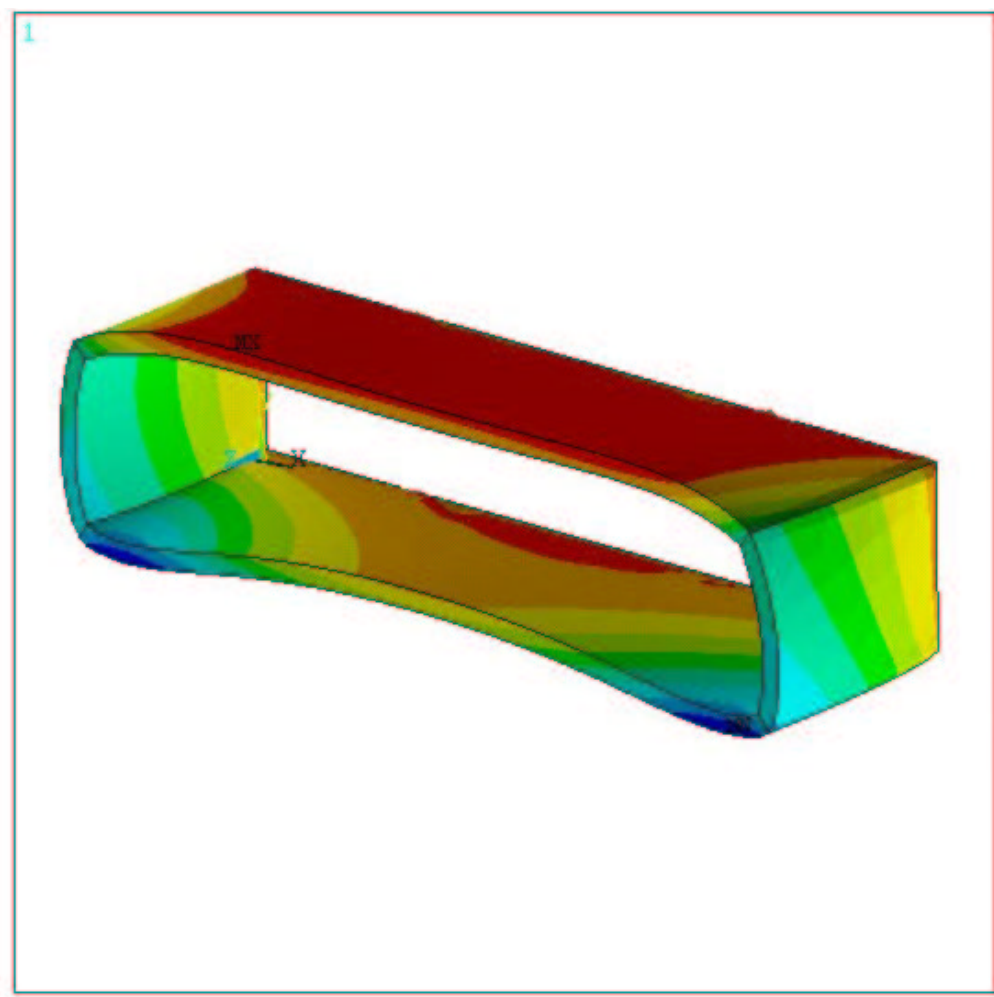

ANSYS $5.5 \cdot 3$

MAY 102001

$11: 18: 43$

NODAL SOLUTION

$\mathrm{STEP}=1$

SUB $=1$

T IME $=1$

UY

(AVG)

RSYS $=0$

PowerGraphics

EFACET $=1$

AVRES $=$ Mat

$\mathrm{DMX}=.800 \mathrm{E}-06$

$\mathrm{SMN}=-.775 \mathrm{E}-06$

$\operatorname{SMX}=.186 \mathrm{E}-06$

$-.775 \mathrm{E}-06$

$-.668 \mathrm{E}-06$

$-.561 \mathrm{E}-06$

$-.454 \mathrm{E}-06$

$-.347 \mathrm{E}-06$

$-.241 \mathrm{E}-06$

$-.134 \mathrm{E}-06$

$-.271 \mathrm{E}-07$

$.796 \mathrm{E}-07$

$.186 \mathrm{E}-06$ 
Fermi National Accelerator Laboratory

Giobatta Lanfranco Silicon Engineering Group - Mechanical Dep.

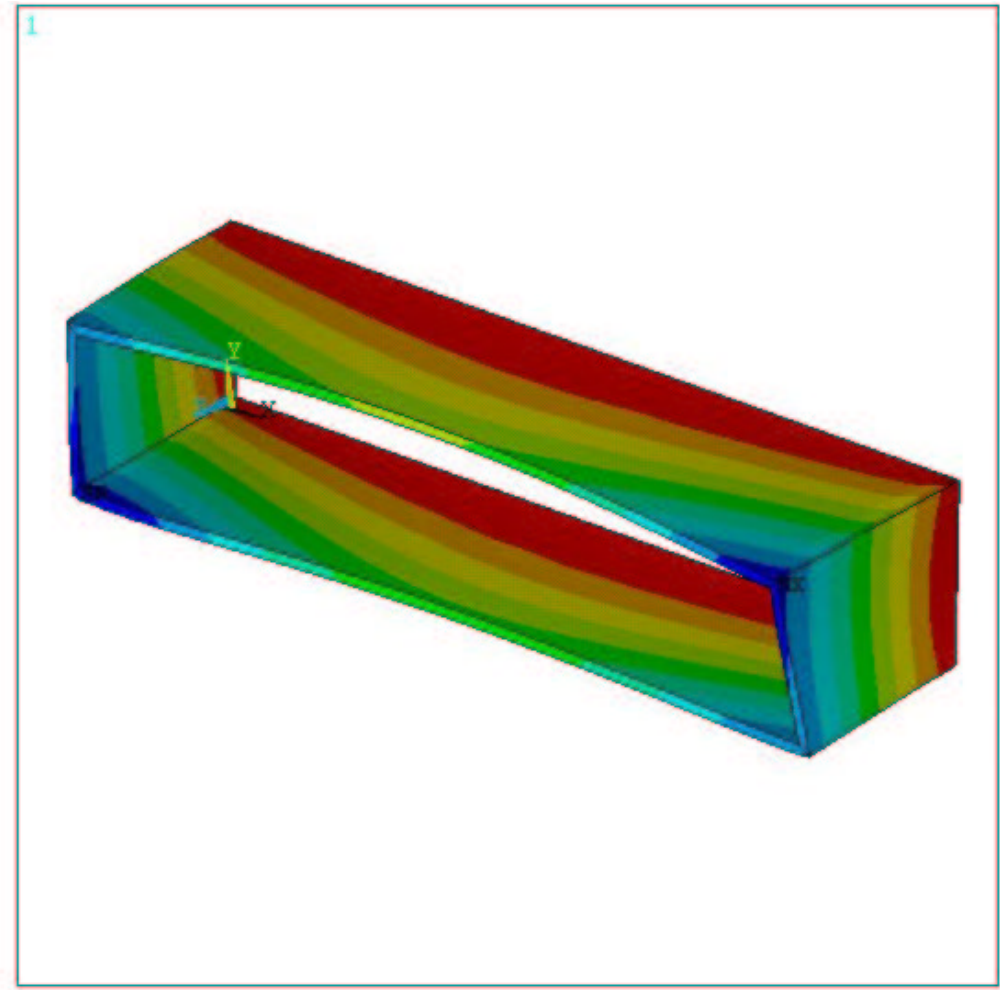

ANSYS 5.5 .3

MAY $10 \quad 2001$

$11: 03: 38$

NODAL SOLUTION

$\mathrm{STEP}=1$

SUB $=1$

TIME $=1$

UY

(AVG)

RSYS $=0$

PowerGraphics

EFACET $=1$

AVRES $=$ Mat

$\mathrm{DMX}=.184 \mathrm{E}-04$

$\mathrm{SMN}=-.166 \mathrm{E}-04$

$\mathrm{SMX}=.661 \mathrm{E}-07$

$-.166 \mathrm{E}-04$

$-147 \mathrm{E}-04$

$-.129 \mathrm{E}-04$

$-.129 \mathrm{E}-04$
$-.110 \mathrm{E}-04$

$-.917 \mathrm{E}-05$

$-.732 \mathrm{E}-05$

$-.548 \mathrm{E}-05$

$-.363 \mathrm{E}-05$

$-.178 \mathrm{E}-05$

$.661 \mathrm{E}-07$

Figure 11 - Material Configuration 2, Load Case 1

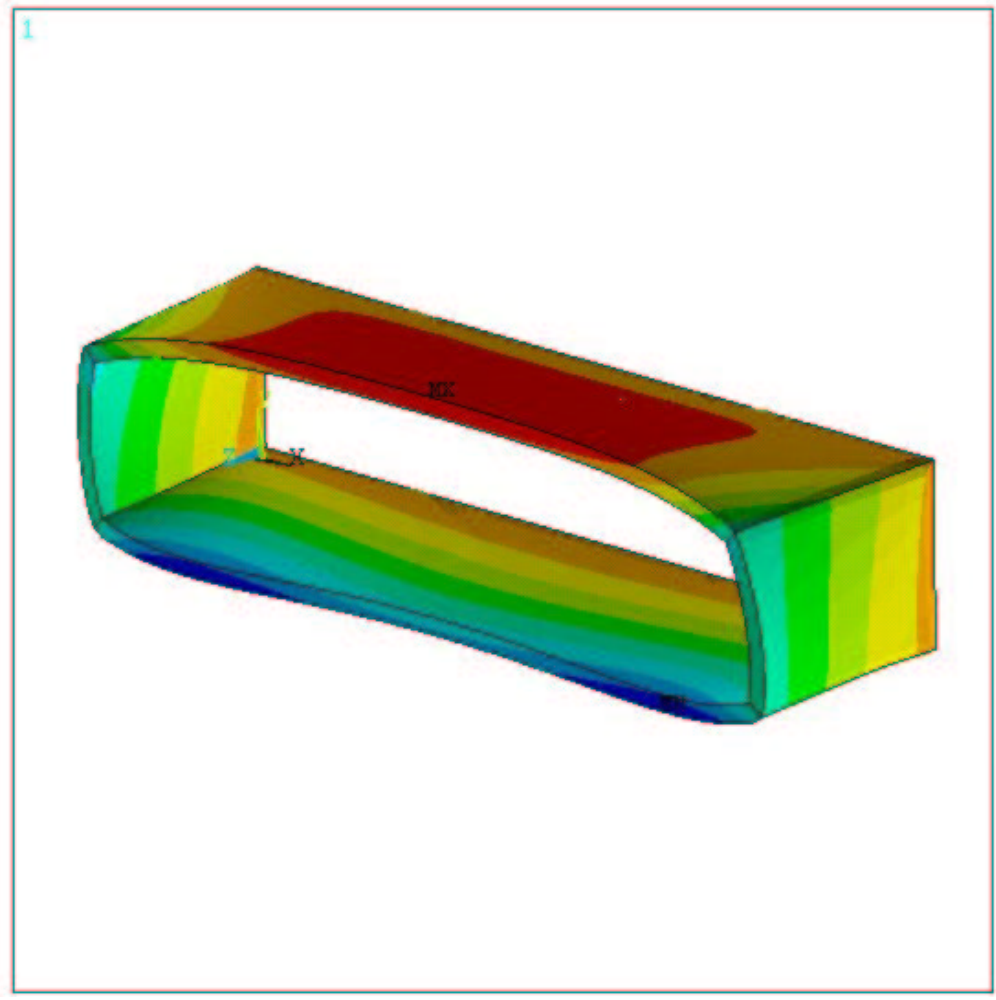

ANSYS $5 \cdot 5 \cdot 3$

MAY 102001

11:13:05

NODAL SOLUTION

$\mathrm{STEP}=1$

SUB $=1$

TIME $=1$

UY

(AVG)

RSYS $=0$

PowerGraphics

EFACET $=1$

AVRES $=$ Mat

$\mathrm{DMX}=.110 \mathrm{E}-0.5$

$\mathrm{SMN}=-.110 \mathrm{E}-05$

$\operatorname{SMX}=.259 \mathrm{E}-06$

$-.110 \mathrm{E}-05$

$-.946 \mathrm{E}-06$

$-.795 \mathrm{E}-06$

$-.644 \mathrm{E}-06$

$-.494 \mathrm{E}-06$

$-.343 \mathrm{E}-06$

$-.192 \mathrm{E}-06$

$-.419 \mathrm{E}-07$

$109 \mathrm{E}-06$

$.259 \mathrm{E}-06$

Figure 12 - Material Configuration 2, Load Case 2 
Fermi National Accelerator Laboratory

Giobatta Lanfranco Silicon Engineering Group - Mechanical Dep.

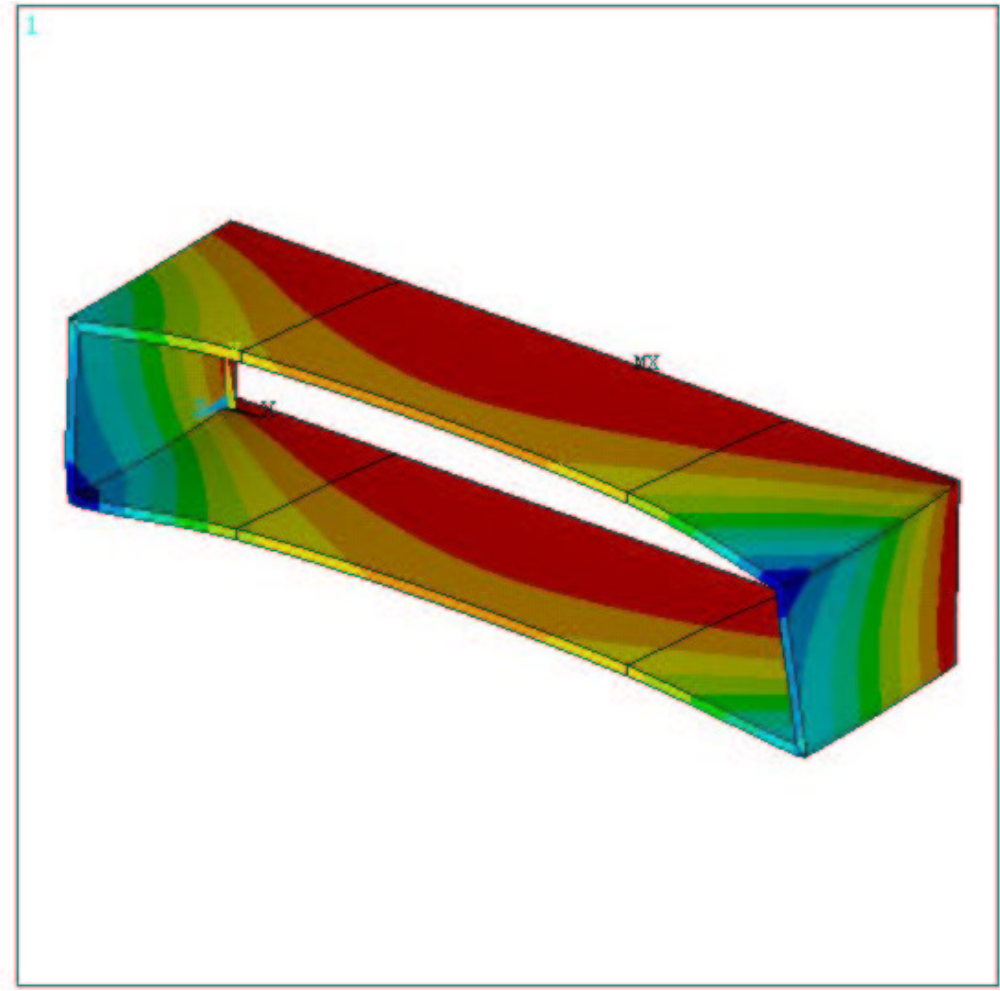

ANSYS $5 \cdot 5 \cdot 3$

MAY $10 \quad 2001$

$10: 41: 54$

NODAL SOLUTION

$\mathrm{STEP}=1$

SUB $=1$

TIME $=1$

UY

(AVG)

RSYS $=0$

PowerGraphics

EFACET $=1$

AVRES $=$ Mat

$\mathrm{DMX}=.132 \mathrm{E}-04$

$\mathrm{SMN}=-.128 \mathrm{E}-04$

$\mathrm{SMX}=.812 \mathrm{E}-07$

$-.128 \mathrm{E}-04$

$-.114 \mathrm{E}-04$

$-.994 \mathrm{E}-05$

$-.994 \mathrm{E}-05$
$-.850 \mathrm{E}-05$

$-.707 \mathrm{E}-05$

$-.564 \mathrm{E}-05$

$-.421 \mathrm{E}-05$

$-.278 \mathrm{E}-05$

$-.135 \mathrm{E}-05$

$.812 \mathrm{E}-07$

Figure 13 - Material Configuration 3, Load Case 1

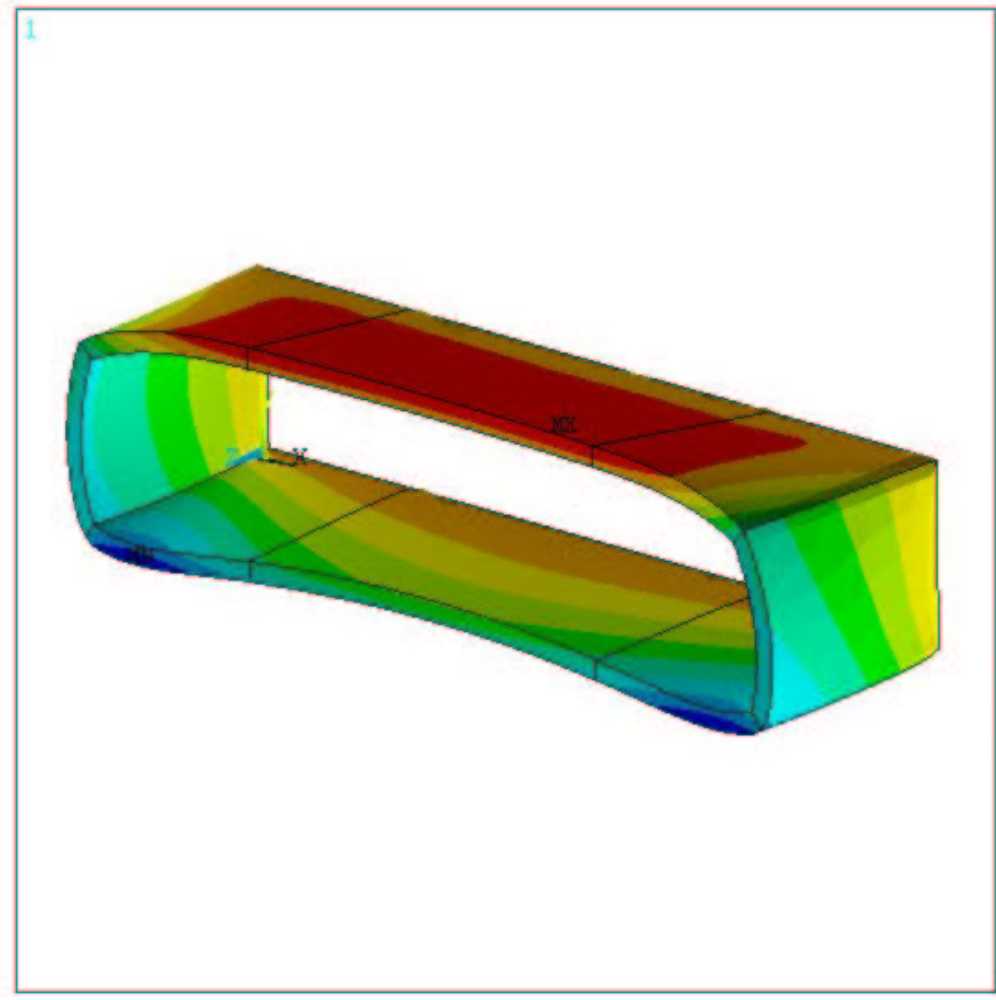

ANSYS $5 \cdot 5 \cdot 3$

MAY 102001

$11: 29: 58$

NODAL SOLUTION

$\mathrm{STEP}=1$

SUB $=1$

TIME $=1$

UY

(AVG)

RSYS $=0$

PowerGraphics

EFACET $=1$

AVRES $=$ Mat

$\mathrm{DMX}=.795 \mathrm{E}-06$

SMN $=-.772 \mathrm{E}-06$

SMX $=.214 \mathrm{E}-06$

$-.772 \mathrm{E}-06$

$-.662 \mathrm{E}-06$

$-.553 \mathrm{E}-06$

$-.443 \mathrm{E}-06$

$-.334 \mathrm{E}-06$

$-.224 \mathrm{E}-06$

$-.115 \mathrm{E}-06$

$-.527 \mathrm{E}-08$

$.104 \mathrm{E}-06$

$.214 \mathrm{E}-06$

Figure 14 - Material Configuration 3, Load Case 2 
Fermi National Accelerator Laboratory

Giobatta Lanfranco Silicon Engineering Group - Mechanical Dep.

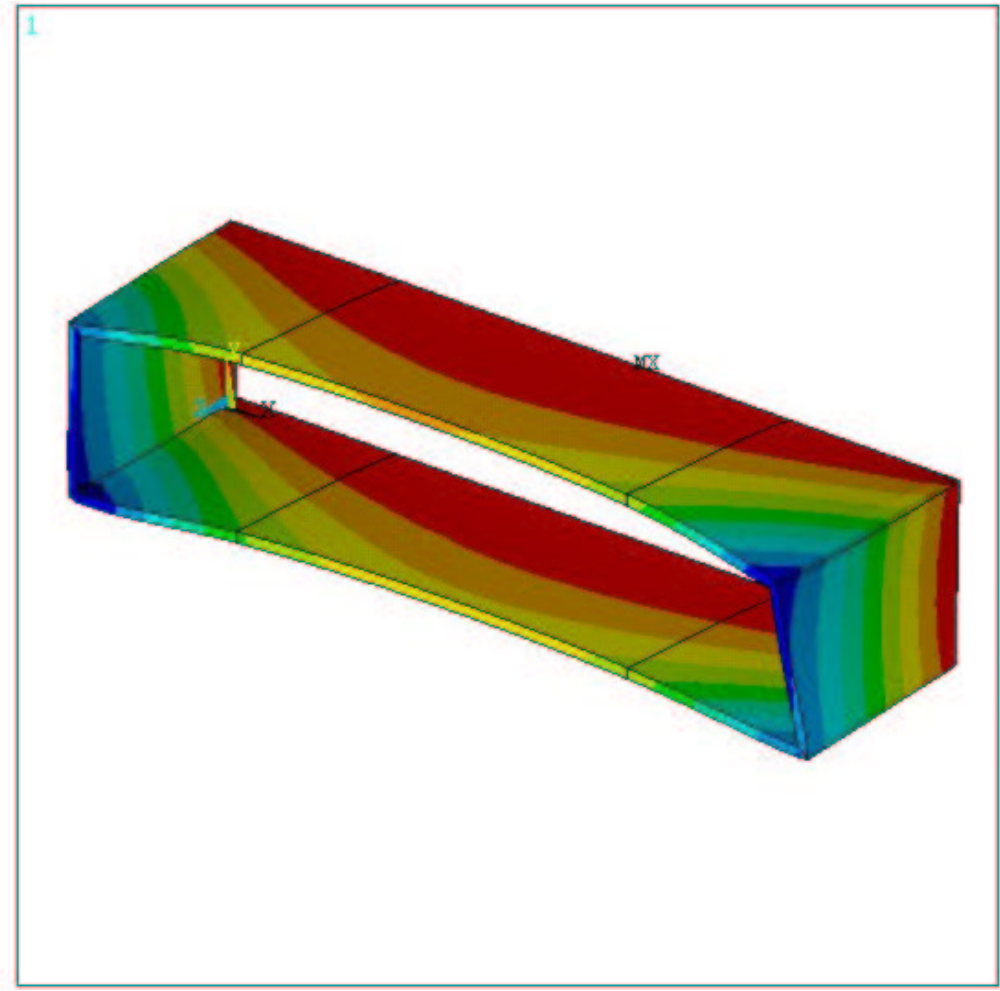

ANSYS 5.5 .3

MAY $10 \quad 2001$

$10: 50: 39$

NODAL SOLUTION

$\mathrm{STEP}=1$

SUB $=1$

TIME $=1$

UY

(AVG)

RSYS $=0$

PowerGraphics

EFACET $=1$

AVRES = Mat

$\mathrm{DMX}=.122 \mathrm{E}-04$

$\mathrm{SMN}=-.112 \mathrm{E}-04$

$\mathrm{SMX}=.785 \mathrm{E}-07$

$-.112 \mathrm{E}-04$

$-.996 \mathrm{E}-05$

$-.871 \mathrm{E}-05$

$-.745 \mathrm{E}-05$

$-.620 \mathrm{E}-05$

$-.494 \mathrm{E}-05$

$-.369 \mathrm{E}-05$

$-.243 E-05$

$-118 \mathrm{E}-05$

$.785 \mathrm{E}-07$

Figure 15 - Material Configuration 4, Load Case 1

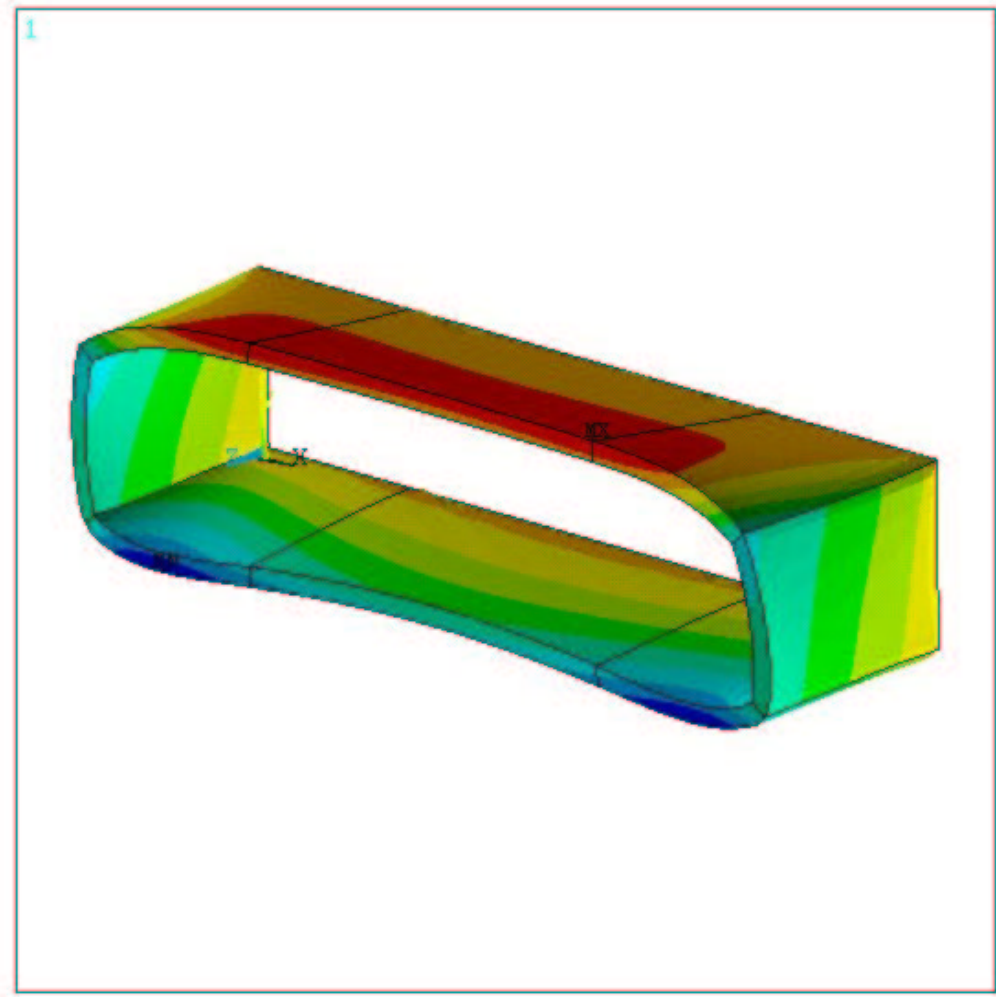

ANSYS $5,5.3$

MAY 102001

$11: 24: 54$

NODAL SOLUTION

STEP $=1$

SUB $=1$

TIME $=1$

UY

(AVG)

RSYS $=0$

PowerGraphics

EFACET $=1$

AVRES $=$ Mat

$\mathrm{DMX}=.815 \mathrm{E}-06$

SMN $=-.793 \mathrm{E}-06$

SMX $=.299 \mathrm{E}-06$

$-.793 \mathrm{E}-06$

$-.671 \mathrm{E}-06$

$-.550 \mathrm{E}-06$

$-.429 \mathrm{E}-06$

$-.307 \mathrm{E}-06$

$-.186 \mathrm{E}-06$

$-.647 \mathrm{E}-07$

$.566 \mathrm{E}-07$

$.178 \mathrm{E}-06$

$.299 \mathrm{E}-06$

Figure 16 - Material Configuration 4, Load Case 2 
Fermi National Accelerator Laboratory

Giobatta Lanfranco Silicon Engineering Group - Mechanical Dep.

\section{Summary and conclusion}

We have studied a proposed stave structure for the D0 Run IIb silicon detector outer layers. Several laminates have been proposed which closely match the thermal expansion coefficient of silicon. Only laminates that incorporate boron fibers can do so while maintaining significant stiffness along the long axis of the stave. The stave design achieves satisfactory stiffness for support at $\sim 0.6 \mathrm{~m}$ intervals. Prototypes should be fabricated and load tested to confirm these results and to investigate the effects of windows in the structure, required to allow for cable penetration and to reduce mass.

\section{Appendix -spreadsheet used for theoretical analysis}

D0 stave structural analysis units: SI

\begin{tabular}{|c|c|c|c|c|c|c|}
\hline & long cf & short cf & beam & silicon & peek & $\mathrm{BeO}^{\star \star \star *}$ \\
\hline b & 43.18 & 0.50 & 4.76 & 37.20 & 6.00 & 35.00 \\
\hline$h$ & 0.25 & 8.64 & 1.78 & 0.30 & 2.00 & 0.50 \\
\hline $\mathrm{xg}$ & 0.00 & 21.34 & 19.21 & 0.00 & 8.49 & 0.00 \\
\hline yg & 4.20 & 0.00 & 0.00 & 1.15 & 0.00 & 1.43 \\
\hline IX & 190.03 & 26.87 & 2.24 & 14.84 & 1.18 & 35.90 \\
\hline ly & 1677.28 & 92.28 & 178.76 & 1286.97 & 119.18 & 1786.46 \\
\hline \#. Pcs & 2.00 & 2.00 & 2.00 & 2.00 & 2.00 & 10.00 \\
\hline Ix tot $\left[\mathrm{mm}^{\star \star} 4\right]$ & 380.05 & 53.75 & 4.47 & 29.69 & 2.36 & 359.01 \\
\hline ly tot $\left[\mathrm{mm}^{\star \star} 4\right]$ & 3354.57 & 184.56 & 357.52 & 2573.94 & 238.36 & 17864.58 \\
\hline$E[G p a]$ & 105.00 & 105.00 & 4.14 & 112.40 & 3.80 & 345.00 \\
\hline$\rho[\mathbf{g} / \mathbf{c c}]$ & 2.20 & 2.20 & 0.32 & 2.33 & 1.42 & 2.85 \\
\hline Load $[\mathrm{N} / \mathrm{m}]$ & 0.186 & 0.186 & 0.053 & 0.510 & 0.334 & \\
\hline Elx $\left[N m^{\star *} 2\right]$ & 39.91 & 5.64 & 0.02 & 3.34 & 0.01 & \\
\hline Ely [N m*2] & 352.23 & 19.38 & 1.48 & 289.31 & 0.91 & \\
\hline$\Sigma$ Elx & 48.913 & & $\Sigma$ Ely & 663.304 & & \\
\hline
\end{tabular}

\begin{tabular}{r|cc} 
& 0.217 coolant load [N/m] \\
Length & $1.2 \mathrm{~m}$ \\
total distributed load & $1.645 \mathrm{~N} / \mathrm{N} / \mathrm{m}$ \\
substrate Load & $0.245 \mathrm{~N}$ & \\
P chip & $0.064 \mathrm{~N}$ & \\
concentrated loads & $0.309 \mathrm{~N}$ & \\
equiv. Distr. Load & $1.903 \mathrm{~N} / \mathrm{m}$ & \\
& & \\
Load [N] & $4.905 \mathrm{~N}$ & \\
Moment [Nm] & $0.113 \mathrm{Nm}$ & \\
y max Si & 1.350 & $18.600 \mathrm{~mm}$ \\
y max CF & 4.000 & $20.000 \mathrm{~mm}$
\end{tabular}


simply supported at the ends

\begin{tabular}{|c|c|c|c|}
\hline Dwn Weight & $\mathbf{x}$ & $\mathbf{Y}$ & \\
\hline $\max \mathrm{sag}$ & 1050 & 77 & micron \\
\hline $\mathrm{Ra} \& \mathrm{Rb}$ & 1.14 & & $\mathrm{~N}$ \\
\hline$M @ x=a$ & 0.34 & & $\mathrm{Nm}$ \\
\hline$n$ from $M^{* *}$ & 1.06 & 1.08 & $\mathrm{Nmm}^{\star *} 2$ \\
\hline CF from $M$ & 2.94 & 1.08 & $\mathrm{Nmm}^{* * 2}$ \\
\hline stres & 1.06 & 1.08 & $\mathrm{Nmm}^{\star *} 2$ \\
\hline & 2.94 & 1.08 & $\mathrm{Nmm}^{* * 2}$ \\
\hline frequency & 19.64 & 72.33 & Hertz \\
\hline
\end{tabular}

central LOAD

\begin{tabular}{|c|c|c|c|}
\hline nax sag! & 3610 & 266 & micron \\
\hline $\mathrm{Ra} \& \mathrm{Rb}$ & 2.45 & & $\mathrm{~N}$ \\
\hline D) $x=a$ & 1.47 & & $\mathrm{Nm}$ \\
\hline $\mathrm{m} \mathrm{M}^{*}$ & 4.56 & 4.64 & $\mathrm{Nmm}^{\star *} 2$ \\
\hline $\mathrm{m} \mathrm{M}$ & 12.64 & 4.66 & $\mathrm{Nmm}^{\star *} 2$ \\
\hline & 4.56 & 4.64 & $\mathrm{Nmm}^{* * 2}$ \\
\hline & 12.64 & 4.66 & $\mathrm{Nmm}^{\star \star 2} 2$ \\
\hline
\end{tabular}

Concentrated MOMENT at the ends

max sag

$\mathrm{Ra}[\mathrm{Rb}=-\mathrm{Ra}]$

Max internal $\mathrm{M}$

Max bending stress in silicon from $\mathrm{M}^{\star *}$

Max bending stress in CF from M $0.97 \quad 0.36 \quad \mathrm{Nmm}^{* * 2}$

Si MOMENT stress $0.35 \quad 0.36 \quad \mathrm{Nmm}^{\star *} 2$

CF MOMENT stress $0.97 \quad 0.36 \quad \mathrm{Nmm}^{\star *} 2$

fixed at the ends

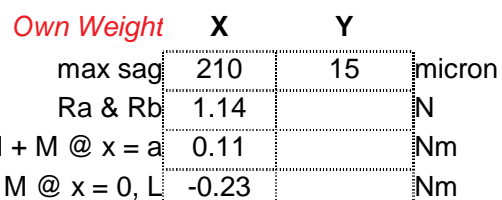

Max bending stress in silicon from $+\mathrm{M}^{* *} \quad 0.35 \quad 0.36 \quad \mathrm{Nmm}^{\star *} 2$

Max bending stress in silicon from $-\mathrm{M}^{* *} \quad 0.71 \quad 0.72 \quad \mathrm{Nmm}^{* *} 2$

\begin{tabular}{l|l|l|l|l|l} 
Max bending stress in CF from $+\mathrm{M}$ & 0.98 & 0.36 & $\mathrm{Nmm}^{* * 2}$
\end{tabular}

\begin{tabular}{l|l|l|l|l} 
Max bending stress in CF from - M & 1.96 & 0.72 & $\mathrm{Nmm}^{* * 2}$
\end{tabular}

Si own weight stress $0.71,0.72 \quad \mathrm{Nmm}^{* * 2}$

CF own weight stress $1.96 \quad 0.72 \quad \mathrm{Nmm}^{* * 2}$

fundamental frequency $43.92,161.72$ Hertz \begin{tabular}{lrr} 
I [m] & \multicolumn{2}{c}{$\mathrm{a}[\mathrm{m}]^{\star}$} \\
& 1.2 & 0.6
\end{tabular}

$\{\mathrm{MPa}\}$

$\{\mathrm{MPa}\}$

$\{\mathrm{MPa}\}$

$\{\mathrm{MPa}\}$

$\{\mathrm{MPa}\}$

$\{\mathrm{MPa}\}$

@

$0.50718 m$

constant along the beam

$\{\mathrm{MPa}\}$

$\{\mathrm{MPa}\}$

$\{\mathrm{MPa}\}$

$\{\mathrm{MPa}\}$ 
Fermi National Accelerator Laboratory

Giobatta Lanfranco Silicon Engineering Group - Mechanical Dep.

Central LOAD
max sag
Ra \& Rb

$\{\mathrm{MPa}\}$

$\{\mathrm{MPa}\}$

\{MPa\}

$\{\mathrm{MPa}\}$

$\{\mathrm{MPa}\}$

$\{\mathrm{MPa}\}$

Concentrated MOMENT at the ends

$\begin{array}{cccc}\max s a g & 0 & 0 & \text { Imicron } \\ \text { Ma, Mb } & 0 & & N \text { Nm }\end{array}$

Max internal $\mathrm{M} @ \mathrm{x}=0$, L Max bending stress in silicon from $-\mathrm{M}^{\star}$

Max bending stress in CF from - $M$

Si MOMENT stress

CF MOMENT stress

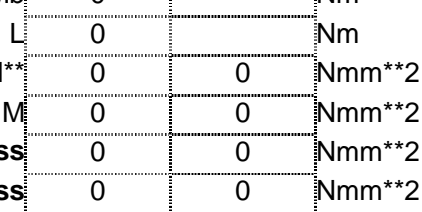

$\{\mathrm{MPa}\}$

$\{\mathrm{MPa}\}$

$\{\mathrm{MPa}\}$

$\{\mathrm{MPa}\}$

simple support at center \& ends

\begin{tabular}{|c|c|c|c|}
\hline Own Weight & & & $\mathbf{Y}$ \\
\hline max sag & 27 & 2 & micron \\
\hline $\mathrm{Ra} \& \mathrm{Rb}$ & 0.43 & & $N$ \\
\hline $\mathrm{Rc}$ & 0.71 & & $N$ \\
\hline Max internal + M @ & 0.05 & & $\mathrm{Nm}$ \\
\hline Max internal - M @ x=L/2 & -0.09 & & $\mathrm{Nm}$ \\
\hline stress in silicon from $+\mathrm{M}^{* *}$ & 0.15 & 0.15 & $\mathrm{Nmm}^{* * 2}$ \\
\hline tress in silicon from $-\mathrm{M}^{\star *}$ & 0.27 & 0.27 & $\mathrm{Nmm}^{\star * 2}$ \\
\hline ding stress in $\mathrm{CF}$ from $+\mathrm{M}$ & 1.28 & 0.15 & $\mathrm{Nmm}^{\star * 2}$ \\
\hline ing stress in CF from - M & 0.74 & 0.27 & $\mathrm{Nmm}^{\star \star 2}$ \\
\hline Si own weight stress & 0.27 & 1.74 & $\mathrm{Nmm}^{* * 2}$ \\
\hline CF own weight stress & 1.28 & 1.75 & $\mathrm{Nmm}^{\star * 2}$ \\
\hline fundamental frequency & 121.93 & 449.01 & Hertz \\
\hline
\end{tabular}

\begin{tabular}{|c|c|c|c|}
\hline Central LOAD & & & \\
\hline $\max$ sag & 202 & 15 & micron \\
\hline $\mathrm{Ra} \& \mathrm{Rb}$ & 1.53 & & $N$ \\
\hline $\mathrm{Rc}$ & 3.37 & & $\mathrm{~N}$ \\
\hline $\mathrm{Mc}$ & 0.55 & & $\mathrm{Nm}$ \\
\hline Max internal + M@x=a & 0.46 & & $\mathrm{Nm}$ \\
\hline Max internal - M (@x = L/2 & -0.55 & & $\mathrm{Nm}$ \\
\hline stress in silicon from $+\mathrm{M}^{\star *}$ & 1.43 & 1.45 & $\mathrm{Nmm}^{\star * 2}$ \\
\hline $\mathrm{g}$ stress in silicon from $-\mathrm{M}^{* \star *}$ & 1.71 & 1.74 & $\mathrm{Nmm}^{\star * 2}$ \\
\hline ending stress in CF from $+\mathrm{M}^{2 m}$ & 3.95 & 1.46 & $\mathrm{Nmm}^{\star \star 2} 2$ \\
\hline ding stress in CF from - Mi & 4.74 & 1.75 & $\mathrm{Nmm}^{* * 2}$ \\
\hline Si LOAD stress & 1.71 & 1.74 & $\mathrm{Nmm}^{* * 2}$ \\
\hline CF LOAD stress & 4.74 & 1.75 & $\mathrm{Nmm}^{* \star 2}$ \\
\hline
\end{tabular}

@

$0.27 m$ 
Fermi National Accelerator Laboratory

Giobatta Lanfranco Silicon Engineering Group - Mechanical Dep.

\begin{tabular}{|c|c|c|c|c|c|}
\hline \multicolumn{6}{|l|}{ Concentrated MOMENT at the ends } \\
\hline max sag & 31 & 2 & micron & $@$ & $0.2 \mathrm{~m}$ \\
\hline $\mathrm{Ra} \& \mathrm{Rb}$ & -0.28 & & $N$ & & \\
\hline $\mathrm{Rc}$ & 0.57 & & $N$ & & \\
\hline Max internal + M @x=0, L & 0.11 & & $\mathrm{Nm}$ & & \\
\hline ax bending stress in silicon from $+\mathrm{M}^{\star *}$ & 0.35 & 0.36 & $\mathrm{Nmm}^{\star * 2}$ & $\{\mathrm{MPa}\}$ & \\
\hline Max bending stress in $\mathrm{CF}$ from $+\mathrm{M}$ & 0.97 & 0.36 & $\mathrm{Nmm}{ }^{\star * 2}$ & $\{\mathrm{MPa}\}$ & \\
\hline Si MOMENT stress & 0.35 & 0.36 & $\mathrm{Nmm}^{* * 2}$ & $\{\mathrm{MPa}\}$ & \\
\hline CF MOMENT stress: & 0.97 & 0.36 & $\mathrm{Nmm}^{\star * 2}$ & $\{\mathrm{MPa}\}$ & \\
\hline
\end{tabular}

\section{NOTES}

${ }^{*} \mathrm{a}$ is half the distance between supports

${ }^{* *}$ compare to $120 \mathrm{MPa}$ Compressive Yield Strength \& $586 \mathrm{MPa}$ Max Tensile Strength for Si

and 2.93 GPa Compressive Yield Strength, 1.5GPa Max Tensile Strength, 1.8 GPa Max Flexural Strength for Boron CF ${ }^{* * *} 50 \mathrm{~mm}$ long in $\mathrm{z}$ (it is not kept into account as a structural member) 